\title{
Building capacity to implement tobacco-free policies in college and university settings with underserved populations
}

\author{
Jessica M. Rath ${ }^{1,2}$, Lindsay Pitzer', Brittany Carnegie' ${ }^{1}$, Muftau Shinaba ${ }^{1}$, Donna Vallone ${ }^{1,2,3}$, Ines Parks ${ }^{4}$, Kristen Tertzakian ${ }^{4}$, \\ Denise Smith ${ }^{4}$, Cianti Stewart-Reid" Elizabeth C. Hair ${ }^{1,2}$
}

\begin{abstract}
INTRODUCTION This study aimed to facilitate the process of policy adoption and implementation across community colleges and Historically Black Colleges and Universities (HBCUs) to develop, adopt, and implement a 100\% smoke- or tobacco-free policy.

METHODS In total, 135 community colleges and HBCUs took part in the program. This multiple-site case study analyzed each institution's online self-reported surveys every 6 months to record progress on each of five core project elements. Data were analyzed in June 2017.

RESULTS Overall, 77 of 135 institutions adopted a smoke- or tobacco-free policy during the college initiative program that led to a broader public health impact of more than 717000 students and employees protected from the harms of smoking and secondhand smoke. A regression analysis also found that ongoing/completed policy activities and perceived importance of having a $100 \%$ smoke- or tobaccofree policy presented greater odds of an institution passing or adopting a policy. CONCLUSIONS Population-level impact and total number of people reached by this initiative is notable, though moving smoking off campus can have unintended impacts. This suggests policy change should include cessation efforts, policy compliance and policies into the broader community when possible through community partnerships.
\end{abstract}

\begin{abstract}
AFFILIATION
1 Schroeder Institute at Truth Initiative, Washington, DC, United States

2 Department of Health, Behavior and Society, Johns Hopkins Bloomberg School of Public Health, Baltimore, MD, United States 3 College of Global Public Health, New York University, New York, NY, United States

4 Truth Initiative, Washington, DC, United States
\end{abstract}

\section{CORRESPONDENCE TO}

Jessica M. Rath. Schroeder Institute at Truth Initiative, Washington, DC, United States.

E-mail: jrath@truthinitiative.org

KEYWORDS

policy, advocacy, tobacco-free

Received: 10 January 2019

Revised: 27 February 2019

Accepted: 15 March 2019

\section{INTRODUCTION}

The decline in youth lifetime cigarette use is well established $^{1}$; however, national surveillance data (2017) reveal that a majority $(57.9 \%)$ of young adults aged 18-25 years still report lifetime use of a tobacco product, with roughly one-quarter $(22.3 \%)$ of them using a cigarette in the past 30 days $^{2}$. In addition, findings suggest that smoking initiation has increased among young adults ${ }^{3}$. During young adulthood, environments such as college campuses where experimentation with substances including tobacco, alcohol and illicit drugs, can facilitate initiation that help establish continued tobacco use and lifetime use of tobacco ${ }^{4}$. According to Monitoring the Future ${ }^{5}$, nearly 1 in 5 college students (18.7\%) used a cigarette in 2016 , and $8.9 \%$ were past 30 -day smokers. Furthermore, roughly 5 in 6 college students are exposed to secondhand smoke in a given week ${ }^{6}$.

One strategy to reduce tobacco use among this age group is to enact and enforce tobacco-free or smoke-free policies within campus boundaries. Although several anti-tobacco interventions have focused on changing individuals' knowledge, attitudes, and beliefs, there is an established literature that demonstrates the broad efficacy of implementing smoke-free (cigarette free) or tobacco-free (free of all tobacco products including cigarettes) policies to decrease prevalence rates 
and reduce smoking behavior across a variety of contexts and geographical areas ${ }^{7,8}$. Neither smokeor tobacco-free policies include electronic smoking devices or hookah. By coordinating resources and support via multiple sources (e.g. community health departments, student governments, college administration), college campuses are in a unique position to empower students, faculty, and staff to participate in efforts towards a healthier life and environment. Policies that restrict tobacco use have been found effective in helping to maintain a safe and healthy learning environment ${ }^{9}$. In fact, the American College Health Association ${ }^{10}$ recommended that all colleges and universities adopt a $100 \%$ tobacco-free campus policy. As a result, support for these smoke- or tobacco-free policies has significantly increased over the last decade. For example, the number of $100 \%$ smoke- or tobaccofree campuses increased to 2164 in April 2018, from 446 in $2010^{11}$.

The success of implementing tobacco restrictions across more than 2000 institutions provides compelling evidence that college campuses can be an important context in which to reduce the likelihood of young adults starting to use tobacco, prompting and aiding tobacco users to quit, and reducing exposure to secondhand smoke ${ }^{12,13}$. However, implementing tobacco-related policies requires a concerted effort to bring together many sectors of the campus community to engage in this process ${ }^{14}$. Evaluation efforts have identified the following facilitators to successful policy implementation, including: 1) creating a committee with representatives from various campus groups, 2 ) establishing venues to foster student debate, 3 ) developing a comprehensive communication plan, 4) drafting policies for review and comment, and 5) reaching out to key stakeholders in the campus community. Barriers include: 1) lack of involvement, among students, faculty, and administrative staff; and 2) insufficient resources ${ }^{9}$. The University of Kentucky embraced these recommendations by establishing a three-pronged approach that included the three 'Ts'. These included: 1) Telling communication and timely notification of the policy; 2) Treating - providing evidence-based tobacco treatment services (free nicotine replacement coupons, group and individual counseling options); and 3) Training - train the campus community on the policy and how to approach violators ${ }^{15}$. Once the policy was passed and implemented, demand for tobacco treatment services on its campus increased and there was a 4 -fold increase in quit attempts and treatment use per month ${ }^{15}$.

Despite the many success stories, the majority of US campuses have yet to implement a comprehensive smoke- or tobacco-free policy, particularly among those institutions predominantly serving lower income and racial/ethnic minority students. Data indicate that only $19 \%$ of community colleges and only one-third of the 102 federally-recognized Historically Black Colleges and Universities (HBCUs) have established tobacco- or smoke-free policies ${ }^{11}$. The higher rates of tobacco use among lower income and racial/ethnic minority college students highlight the critical need for policy implementation at these institutions. For example, a Minnesota study found that two-year college students are twice as likely to use tobacco products compared to four-year college students ${ }^{16}$. National data reflect comparable results: $15.5 \%$ of individuals with an associate's degree were current cigarette smokers compared to $7.1 \%$ with an undergraduate degree ${ }^{17}$. Furthermore, multiple data sources on HBCUs found that $35 \%$ of students knew an immediate family member who smoked cigarettes, more than half reported having a close friend who smoked, and $62 \%$ of smokers preferred menthol cigarettes ${ }^{18,19}$.

In the past, community colleges and HBCUs have experienced significant barriers to adoption of these comprehensive policies compared to traditional fouryear institutions. These colleges often face a lack of institutional support, and a lack of resources to help build support for these initiatives. Nonetheless, there is a critical need given that these institutions often serve as a gateway to postsecondary education for many minority, low-income, and first-generation postsecondary education students, serving almost two-fifths of the US undergraduate population ${ }^{20}$. In addition, African-American individuals, who comprise more than three-fourths of the student population at HBCUs, are more likely to die from tobacco-related disease and are less successful at smoking cessation, despite having higher quit attempts, compared to White and Hispanic peers ${ }^{21-24}$. These students, many of whom come from lower 
income and racial/ethnic minority groups, have been also targeted by the tobacco industry. Compelling evidence indicates that those living in lower income neighborhoods are exposed to a higher level of protobacco advertising compared to higher income neighborhoods ${ }^{25,26}$. Thus, smoke- or tobacco-free policies can serve as a critical intervention for those in contexts that otherwise may promote tobacco use.

The goal of the College Initiative Program was to use the five evidence-based steps of successful policy implementation ${ }^{9}$ to help facilitate the process of policy adoption and implementation across 115 institutions (75 community colleges and 40 HBCUs) to develop, adopt, and implement a $100 \%$ smoke- or tobacco-free policy by the end of the grant period.

\section{METHODS}

In 2014, the College Initiative Program was established as a comprehensive program that included technical assistance (i.e. materials, webinars, and institution-specific counseling) as well as grant awards to qualified colleges and universities for $100 \%$ smoke- or tobacco-free policy adoption and implementation efforts. To build awareness of this program, team members engaged stakeholders, attended conferences, and visited individual campuses to highlight the components of the program and encourage the submission of applications. Once a broad informational effort was completed, a request for proposals (RFP) was released via listservs, stakeholders, online discussion boards, college steering committees, and direct outreach. A selection process, which included a committee of both employees and external professionals, was developed to review and score each application.

During the pilot phase, 5 HBCUs were chosen to help program developers refine processes and procedures for this new initiative. Once the pilot phase was completed, subsequent rounds of applications yielded a total 135 institutional program participants. Each institution was asked to develop a plan to comprehensively address five core elements: 1) policy activities including campus taskforce membership; 2) campus environment surveys (disseminated to students, staff and other personnel) on tobacco use and related knowledge, attitudes, beliefs and awareness of health implications; 3 ) engage campus stakeholders in all steps of the process; 4) provide or promote cessation services; and 5) policy implementation and adoption plan?.

\section{Support services}

Technical assistance was available for every grantee that included tobacco related training and informational materials, webinars, and institutionspecific counseling. Each HBCU cohort received a kick-off training to educate participants about tobacco control and prepare them for implementation of each of the five core project elements. Community colleges did not receive this training but had an opportunity to learn the materials through an online learning community. This community was established to provide training, facilitate collaboration among institutions, share information, highlight successes, and ask questions. This web-based mechanism also provided a platform for posting webinar recordings and any other useful documentation for grantees. Web analytics (total pages viewed) were used to measure aggregated engagement in the online community by all institutional participants.

\section{Evaluation design}

An evaluation was conducted by an external organization specializing in capacity building. This organization helped develop research questions and set program goals for the college initiative program. It was responsible for conducting all evaluation activities, which began with developing a programmatic logic model to guide program planning, implementation and evaluation. The process evaluation consisted of assessing progress with three distinct data collection methods including: 1) self-reported structured survey reports, 2) in-depth interviews, and 3) engagement in online learning communities.

Online progress reports were completed every 6 months from 2015 to 2017 . Each institution received a link to an online Qualtrics survey via email to record progress with respect to each of the five core project elements. Most questions were closed-ended to reduce participant burden and were standardized across institutions.

\section{Measures}

\section{Policy activities}

Colleges were asked about the status of various policyrelated activities including development activities 
(e.g. creating a taskforce), implementation activities (e.g. submitting policy for approval), and enforcement activities (e.g. enforcing policy). Community colleges rated 19 activities while HBCUs rated 1 additional activity. Respondents provided the level of progress their college had made for each activity (Have Not Conducted, Planning or Beginning Activity, Completed Activity, or Ongoing Activity). A composite variable to categorize the college's level of activity as ongoing and/or completed was created.

\section{Task force functioning}

Participant institutions reported progress towards taskforce development and functioning on a scale of 1 (strongly disagree) to 5 (strongly agree) for a total of 5 items. These items included the level of commitment, common vision and mission, targeted action-planning, clear and efficient communication, and progress toward project goals and activities.

\section{Campus environment readiness for policy change}

Participant institutions rated perceived level of readiness for policy change on campus. Questions assessed the extent to which college members (students, faculty, and administration) were aware of the $100 \%$ smoke- or tobacco-free policy efforts, felt that tobacco use is acceptable on campus, and felt that having a $100 \%$ smoke- or tobacco-free policy is important. Response options ranged from 1 (Little or None) to 4 (A Great Deal).

\section{Awareness of health implications}

Participant institutions reported on perceived level of awareness of health implications of tobacco use and secondhand smoke exposure. The questions assessed the extent to which college members were concerned about the health consequences of secondhand smoke, recognized tobacco use as a serious health risk, and felt that a $100 \%$ smoke- or tobacco-free policy would create a healthier campus. Response options ranged from 1 (Little or None) to 4 (A Great Deal).

Knowledge and skills to adopt and implement policies Participant institutions rated the perceived level of knowledge and skills among taskforce and college members for adopting and implementing their policies. The questions assessed the extent to which their taskforce understood the steps needed to adopt and implement the policy, clear and effective messages were developed to promote the policy, college members were involved in the development of the policy, and campus administration understood the structural and system changes needed to implement the policy. Response options ranged from 1 (Little or None) to 4 (A Great Deal).

Campus support for $100 \%$ smoke- or tobacco-free policies

College grant leads rated the perceived level of support for $100 \%$ smoke- or tobacco-free policies among college members. They were asked to separately rate the extent to which they thought there was support for the $100 \%$ smoke- or tobaccofree policy by students, faculty and administration. Response options ranged from 1 (Little or None) to 4 (A Great Deal).

\section{Adoption of 100\% smoke- and tobacco-free policy}

College grant leads reported on the status of their $100 \%$ smoke- or tobacco-free policy (i.e. if policy had been adopted, yes/no). They were also asked to share the date of adoption and a copy of the final adopted policy as part of their progress report. Institutions that consisted of multiple campuses were encouraged to adopt a college-wide policy to have an impact on all campuses and centers.

\section{Outreach/education channels}

Participants reported on their progress specific to 20 activities using the scale: 1) have not conducted, 2) planning or beginning activity, 3 ) ongoing activity, or 4) completed activity. Activities included education and communication activities (town halls, institution website and paper, social media, press conferences and petitions), as well as other meetings related to policy implementation.

\section{Programmatic duration}

Programmatic period was calculated in months to account for the varying amounts of time that each institution participated in the program.

\section{RESULTS}

We employed an 'intent-to-treat' approach ${ }^{28}$, which allowed for the inclusion of all colleges that participated in the initiative $(n=135)$ regardless of when they 
began the program. In total, $87 \%(n=117)$ of all colleges and universities either started or completed forming their smoke- or tobacco-free taskforce and thought that their taskforce was functioning at a high level (Table 1). Of the 135 institutions, the majority completed their campus assessment efforts ( $n=83,62 \%$ ) while $22 \%$ developed their own campus assessment $(\mathrm{n}=30)$. An overwhelming majority $(95 \%)$ of all colleges reported engaging in at least two education and awareness activities, but only $40 \%$ reported engaging in at least two earned media activities (e.g. college websites, listservs). Platforms such as college websites, social media, and the campus newspaper were the most commonly reported media venues, while local and campus radio, and campus television were among the least likely to be used. A total of 77 of 135 institutions fully adopted a smokeor tobacco-free policy during the college initiative program and a total of 110 institutions presented a $100 \%$ smoke- or tobacco-free policy recommendation to key campus decision makers (e.g. shareholders, regents) by the end of the program.

In terms of campus environment support, all participant institutions rated awareness of efforts $(\mathrm{M}=3.13)$ and importance of policy $(\mathrm{M}=3.19)$ as moderately high. Moreover, ratings were low $(\mathrm{M}=2.09)$ for colleges that felt that tobacco use is acceptable on campus. Most participants rated awareness of tobacco's health implications as a moderate to high concern of college members about the health consequences of secondhand smoke ( $M=2.98)$, recognition of tobacco use as a serious health risk $(\mathrm{M}=3.27)$, and the belief that a $100 \%$ smoke- or tobacco-free policy would create a healthier campus $(\mathrm{M}=3.33)$. There were high levels of knowledge and skills to adopt and implement a $100 \%$ smoke- or tobacco-free policy $(\mathrm{M}=3.33)$ and campus support for these policies among colleges was rated as moderately high $(\mathrm{M}=3.14)$, with the greatest amount of support coming from the administration $(\mathrm{M}=3.22)$ and the least amount of support coming from students $(\mathrm{M}=3.06)$.

\section{Support services}

Every HBCU cohort received a kick-off training to educate participants about tobacco control and prepare them for implementation of each of the five core project elements. Community colleges did not receive this training. Forty-two per cent of institutions $(n=57)$ used the technical assistance (TA) and webinars with institutions receiving between one and eight check-in calls per year from trained staff. Additionally, over a quarter of college grantees reported 'no networking with other colleges' $(28 \% ; n=39)$, and $24 \%(n=32)$ reported only 'some' networking with other colleges. Eighteen per cent of colleges reported using the online learning community NING $(n=24)$ and NING was found to be, on average, only moderately helpful in promoting information sharing $(\mathrm{M}=3.00)$. The NING resources webpage was the most visited and accounted for $9 \%$ of all page views for the site.

Table 1. Mean levels of campus members attitudes surrounding risks of smoking, taskforce functioning, and the importance of a $100 \%$ smoke- or tobacco-free policy

\begin{tabular}{|c|c|}
\hline Variable & Mean \\
\hline Agreement on taskforce functioning ${ }^{\mathrm{a}}$ & 4.26 \\
\hline Awareness of tobacco-free policy efforts by college members ${ }^{b}$ & 3.13 \\
\hline Extent college members understand the importance of policy ${ }^{b}$ & 3.19 \\
\hline Extent to which campus members feel that tobacco use on campus is acceptable ${ }^{b}$ & 2.09 \\
\hline Concern about the health consequences of secondhand smoke on campus by campus members ${ }^{b}$ & 2.98 \\
\hline Recognition of tobacco as a serious health risk by campus members ${ }^{b}$ & 3.27 \\
\hline Extent to which campus members believe a $100 \%$ smoke- or tobacco-free policy would create a healthier campus ${ }^{b}$ & 3.33 \\
\hline Taskforce has a high level of knowledge and skill to adopt and implement a smoke-free policyb & 3.33 \\
\hline Campus support for smoke-free policy: Overall ${ }^{b}$ & 3.14 \\
\hline Campus support for smoke-free policy: Administration ${ }^{b}$ & 3.22 \\
\hline Campus support for smoke-free policy: Faculty ${ }^{b}$ & 3.13 \\
\hline Campus support for smoke-free policy: Students ${ }^{b}$ & 3.06 \\
\hline
\end{tabular}

a This item was measured on a scale: $1=$ Strongly Disagree, $2=$ Disagree, $3=$ Neither Agree or Disagree, $4=$ Agree, $5=$ Strongly Agree. $b$ These items were measured on a scale: 1 = Little or None, 2 =Some, 3 = A Fair Amount, 4 = A Great Deal. 
Table 2. Results of logistic regression of factors associated with completing or engaging in policy activities

\begin{tabular}{|c|c|c|c|}
\hline Variable & $\boldsymbol{B}$ & $\mathbf{S E}^{B}$ & OR \\
\hline Time involved in grant program & 0.01 & 0.08 & 1.00 \\
\hline Policy activities completed or ongoing & $0.40^{* *}$ & 0.16 & 1.50 \\
\hline Outreach/education channels & 0.01 & 0.15 & 1.01 \\
\hline Task force functioning & 0.60 & 0.66 & 1.81 \\
\hline Importance of having a $100 \%$ smoke- or tobacco-free policy & $1.35^{*}$ & 0.64 & 3.86 \\
\hline Awareness of health implications & -0.69 & 0.76 & 0.50 \\
\hline Knowledge and skills to adopt \&t implement policies & 1.45 & 0.84 & 4.28 \\
\hline Policy support & 1.07 & 0.74 & 2.93 \\
\hline
\end{tabular}

$\left(X^{2}=46.22, d f=8, p<0.05\right) .{ }^{*} p<0.05,{ }^{* *} p<0.01$.

\section{Predictors of successful policy adoption}

A logistic regression examined (8) factors associated with completing or engaging in policy activities: time involved in grant program, policy activities completed or ongoing, outreach/education channels, taskforce functioning, importance of having an 100\% smoke- or tobacco-free policy, awareness of health implications, knowledge and skills to adopt and implement policies, and policy support. The model highlighted that there were two significant predictors of completing or engaging in policy activities: a) policy activities completed or ongoing, and b) perceived importance of having a $100 \%$ smoke- or tobacco-free policy. Specifically, for each additional policy activity either completed or in process, institutions were significantly more likely to adopt a policy $(\mathrm{OR}=1.5)$. Furthermore, colleges had 3.9 times the odds to pass a $100 \%$ smokeor tobacco-free policy for every unit increase in the importance of having a $100 \%$ smoke- or tobacco-free policy on campus (Table 2 ).

\section{DISCUSSION}

Approximately 41000 deaths from secondhand smoke exposure among non-smoking adults occur annually ${ }^{29}$. College and university level policies allow for broad control over the health and welfare of their campus including students, staff, and visitors. Since December 2017, the college initiative program helped 77 institutions adopt a tobacco- and/or smokefree policy. The other 58 institutions are at various stages of policy adoption with 33 institutions already drafting policy recommendations and 8 schools adopting policies after the defined program end date. The three-year initiative was realistic for some institutions while others may take more time to get through necessary processes. This type of population- level tobacco control requires thoughtful planning and multiple stakeholders. The College Initiative Program demonstrates that investing a relatively modest amount of money, technical assistance and guidance in the form of personal communication, templates for examples of successful policy and measurement, and a platform for collaboration across grantees, led to a broader public health impact in the form of more than 717000 students and employees protected from the harms of smoking and secondhand smoke.

In order to continue to improve the program, barriers encountered by those schools that did not adopt a $100 \%$ smoke- or tobacco-free policy by the end of the program provided important information. Three common barriers encountered by colleges included: 1) depleted funding, 2) needing more time, and/or 3) a lack of support or buy-in from stakeholders and decision makers, including faculty groups and the board of trustees. Ten per cent of colleges described resistance from campus community members, especially smokers and policy opponents $(n=14)$. Likewise, $10 \%$ of colleges also had troubles rallying support from key stakeholders in promoting and enforcing the $100 \%$ smoke- or tobacco-free policy across campus $(n=14)$. Twentyone per cent experienced challenges trying to enforce the policy; moreover, 16 colleges requested support to help implement policies and develop procedures to consistently enforce the policy. Enforcement efforts ranged from student and/ or employee volunteers being provided scripts to approach violators to more formal enforcement through fines. In many cases the tobacco-free policy was treated like any other policy under the code of conduct and violations were referred to HR.

Solutions to address these barriers are in progress, 
including an increase in the amount of the initial grants for participating schools and a less stringent deadline for policy adoption. With this barrier reduced from the original three-year timeframe to a more open-ended date, eight additional schools in the original cohort of 135 have informed the program that they have been successful in policy adoption, bringing the total student and employee population protected to 804121 people. To give schools time to adopt a policy outside of the original program goals, efforts would need to be made to determine if additional schools adopted policies and did not inform the program, as requested. Slightly increased funds to future grantees would be offered to decrease the number of schools that depleted funds before passing a policy. The increased funds will also attract the harder to reach schools, typically in states with higher than average smoking prevalence. The technical assistance from staff will include more resources to gain buyin from campus leaders in the form of task force development training as well as webinars that use strategies from similar successful schools as models. This is critical given the predictive nature of the perceived importance of college member's beliefs in the importance of having a policy. Finally, tobacco- or smoke-free colleges and universities are in a good position to motivate other campuses to go tobacco-free and to share strategies for success. In this study, colleges and universities were connected via webinars and customized discussion boards; however, other initiatives may look to optimize methods of connecting schools to motivate each other to go tobacco-free.

\section{Limitations}

This project is not without methodological limitations. There are no control institutions with completed measures to understand if campuses without the program are working towards tobacco-control campus policies. In addition, institutions were self-selected for participation, which may eliminate institutions with great need. Furthermore, institutional turnover resulted in a few school portfolios being handled by multiple people. Also, these findings may not be generalizable to other countries or cultures. Finally, this study did not attempt to evaluate how demographics of the campus (e.g. geographical location, size of campus) may have played a role in completing policy activities. This is an area for future research.

\section{CONCLUSIONS}

While the population level impact and total number of people reached by this initiative is impressive, the project focus was at the campus level. This did not account for the broader community surrounding each location. Moving smoking off campus can have the unintended impact of moving the smoking into neighboring communities. This highlights the need for policy change to include cessation efforts, policy compliance and even an extension of policies into the broader community when possible through community partnerships. Finally, it highlights the need for policy institutionalization on campus to ensure the sustainability of the smoke-free campus. Of the 77 policies, 71 include e-cigarettes in their ban language. Future research should estimate the effects of including or not including e-cigarettes alongside tobacco in their school-wide policies.

\section{REFERENCES}

1. Johnston LD, Miech, R. A., O’Malley, P. M., Bachman, J. G., Schulenberg, J. E., \& Patrick, M. E. Monitoring the Future national survey results on drug use, 1975-2017: Overview, key findings on adolescent drug use. Ann Arbor: Institute for Social Research, The University of Michigan; 2018.

2. Center for Behavioral Health Statistics and Quality. Results from the 2017 National Survey on Drug Use and Health: Detailed Tables. Rockville: MD; 2018.

3. Hair E, Bennett M, Williams V, et al. Progression to established patterns of cigarette smoking among young adults. Drug \& Alcohol Dependence. 2017;177:77-83. doi:10.1016/j.drugalcdep.2017.03.040

4. Wetter DW, Kenford SL, Welsch SK, et al. Prevalence and Predictors of Transitions in Smoking Behavior Among College Students. Health Psychology. 2004;23(2):168177. doi:10.1037/0278-6133.23.2.168

5. Schulenberg JE, Johnston, L. D., O’Malley, P. M., Bachman, J. G., Miech, R. A. \& Patrick, M. E. Monitoring the Future national survey results on drug use, 19752016: Volume II, College students and adults ages 19-55. Ann Arbor: Institute for Social Research, The University of Michigan; 2017.

6. Wolfson M, McCoy TP, Sutfin EL. College students' exposure to secondhand smoke. Nicotine \& Tobacco Research. 2009;11(8):977-984. doi:10.1093/ntr/ntp100

7. Wisotzky M, Albuquerque M, Pechacek TF, Park BZ. The National Tobacco Control Program: Focusing on Policy to 
Broaden Impact. Public Health Reports. 2004;119(3):303310. doi:10.1016/j.phr.2004.04.009

8. Fichtenberg CM, Glantz SA. Effect of smoke-free workplaces on smoking behaviour: systematic review. Bmj. 2002;325(7357):188. doi:10.1136/bmj.325.7357.188

9. Glassman TJ, Reindl DM, Whewell AT. Strategies for implementing a tobacco-free campus policy. Journal of American College Health. 2011;59(8):764-768. doi:10.1080/07448481.2010.529479

10. American College Health Association. Position Statement on Tobacco on College and University Campuses Hanover; MD2011.

11. American Nonsmokers' Rights Foundation. Smokefree and Tobacco-Free U.S. and Tribal Colleges and Univerisities; 2017.

12. Chaloupka FJ, Wechsler H. Price, tobacco control policies and smoking among young adults. J Health Econ. 1997;16(3):359-373. doi:10.1016/s0167-6296(96)00530-9

13. Plaspohl SS, Parrillo AV, Vogel R, Tedders S, Epstein A. An Assessment of America's Tobacco-Free Colleges and Universities. Journal of American College Health. 2012;60(2):162-167. doi:10.1080/07448481.2011.580030

14. Reindl D, Glassman T, Price J, Dake J, Yingling F. Perceptions of college and university presidents regarding tobacco-free campus policies. Journal of American college health : J of ACH. 2014;62(3):193-202. doi:10.1080/07448481.2013.877019

15. Hahn EJ, Fallin A, Darville A, Kercsmar SE, McCann M, Record RA. The three Ts of adopting tobaccofree policies on college campuses. The Nursing clinics of North America. 2012;47(1):109-117. doi:10.1016/j.cnur.2011.11.002

16. Sanem JR, Berg CJ, An LC, Kirch MA, Lust KA. Differences in Tobacco Use Among Two-Year and Four-Year College Students in Minnesota. Journal of American College Health. 2009;58(2):151-159. doi:10.1080/07448480903221376

17. Wang TW, Asman K, Gentzke AS, et al. Tobacco Product Use Among Adults - United States, 2017. MMWR Morbidity and mortality weekly report. 2018;67(44):12251232. doi:10.15585/mmwr.mm6744a2

18. Hayes BD, Holliday RC, Wade BH, et al. A Comprehensive Examination of the Health Knowledge, Attitudes and Behaviors of Students Attending Historically Black Colleges and Universities. Journal of health care for the poor and underserved. 2009;20(20):69-84. doi:10.1353/hpu.0.0159

19. Laws MA, Huang CJ, Brown RF, Richmond A, Conerly RC. Cigarette Smoking Among College Students Attending A Historically Black College and University. Journal of Health Care for the Poor and Underserved. 2006;17(1):143-156. doi:10.1353/hpu.2006.0007

20. American Association of Community Colleges. AACC Fast Facts 2018. Washington, Dc; 2018.

21. National Center for Education Statistics. Fall enrollment in degree-granting historically Black colleges and universities, by sex of student and level and control of institution: Selected years, 1976 through 2016. Digest of Educational Statistics; 2017.

22. American Cancer Society. Cancer Facts \& Figures for African Americans, 2013-2014; 2013.

23. Alexander LA, Trinidad DR, Sakuma KL, et al. Why We Must Continue to Investigate Menthol's Role in the African American Smoking Paradox. Nicotine \& tobacco research: official journal of the Society for Research on Nicotine and Tobacco. 2016;18 Suppl 1:S91-101. doi:10.1093/ntr/ntv209

24. Babb S, Malarcher A, Schauer G, Asman K, Jamal A. Quitting Smoking Among Adults United States, 2000-2015. MMWR: Morbidity \& Mortality Weekly Report. 2017;65(52):1457-1464. doi:10.15585/mmwr.mm6552a1

25. Seidenberg AB, Caughey RW, Rees VW, Connolly GN. Storefront cigarette advertising differs by community demographic profile. Am J Health Promot. 2010;24(6):e26-31. doi:10.4278/ajhp.090618-quan-196

26. Lee JG, Henriksen L, Rose SW, Moreland-Russell S, Ribisl KM. A Systematic Review of Neighborhood Disparities in Point-of-Sale Tobacco Marketing. American journal of public health. 2015;105(9):e8-e18. doi:10.2105/ajph.2015.302777

27. Community Science. About Community Science. 2018; http://www.communityscience.com/about.php. Accessed May 7, 2018.

28. Salim A, Mackinnon A, Christensen H, Griffiths K. Comparison of data analysis strategies for intent-to-treat analysis in pre-test-post-test designs with substantial dropout rates. Psychiatry research. 2008;160(3):335-345. doi:10.1016/j.psychres.2007.08.005

29. US Department of Health and Human Services. The health consequences of smoking: 50 years of progress: a report of the Surgeon General. Atlanta, GA: CDC; 2014.

\section{ACKNOWLEDGEMENTS}

The authors would like to thank Evelyn Yang and Community Science for their efforts on the evaluation design and implementation.

\section{CONFLICTS OF INTEREST}

The authors have completed and submitted the ICMJE Form for Disclosure of Potential Conflicts of Interest and none was reported.

\section{FUNDING}

There was no source of funding for this research.

\section{PROVENANCE AND PEER REVIEW}

Not commissioned; externally peer reviewed. 